appointment to Mr. Edmonds to find that he had been anticipated in this manner, but it may be a consolation to him to reflect that his position is by no means a singular one. There has probably been scarcely a single discovery of any kind made, but some unfortunate man has been on the point of making it too, and would have done so, if he had only bad sufficient time allowed.

In conclusion, I beg to state that in all I have said, I have been influenced by no personal feeling towards Mr. Edmonds. I wish to allow him all the credit justly due to him. I believe that in accomplishing the object he had in view-viz., that of forming a new hypothetical table of mortality-he has shown considerable judgment and skill; and I shall willingly admit the universality of his constants whenever I see sufficient proofs of their accuracy produced. My object has been simply truth; and if, in the course of my remarks, I have been led to use language which may seem severe, I regret the necessity I have been under. I feel I have trespassed rather unreasonably on your space; but trust that what I have said will enable others who have but little time to devote to such subjects, to come to a correct conclusion as to the claims pnt forward by Mr. Edmonds. My task would have been much lighter if Mr. Edmonds had confined himself to an explanation of his own theory; for then I should not have thought it necessary to dwell upon the numerous errors into which be has fallen. This course has been rendered necessary by his uncalled for criticisms of $\mathrm{Mr}$. Gompertz. Your readers will probably be better able to form an opinion as to the proper weight to be assigned to those criticisms, the whole of which I have not thought it necessary to review, when they learn that the writer of them has himself fallen into many serions errors.

$$
\begin{aligned}
& \text { I am, Sir, } \\
& \text { Your obedient servant, }
\end{aligned}
$$

$$
\begin{aligned}
& \text { 25, Pall Mall, } \\
& \text { 7th February, } 1861 .
\end{aligned}
$$

T. B. SPRAGUE.

\title{
EXPRESSION FOR THE VALUE OF A TERM ASSURANCE, HIFE AGAINST LIFE.
}

\section{To the Editor of the Assurance Magazine.}

$\mathrm{Sr}$,-Perhaps the following brief expression for the value of a short period assurance on $(x)$ against $(y)$ may be worth a place in your Journal.

By the combined use of the ordinary Commutation Tables in Jones, and the tables of Gray, Smith, and Orchard, for such an assurance to be cnrrent for $m$ years and paid for in $n$ annual premiums, the formula becomes

$$
\frac{\mathrm{D}_{x y} \mathrm{~A}_{\frac{1}{x, y}}-\mathrm{D}_{x+m, y+m} \mathrm{~A}_{\frac{1}{x+m, y+m}}}{\mathrm{~N}_{x-1, y-1}-\mathrm{N}_{x+n-1, y+n-1}} .
$$

I am, Sir,

Your most obedient Servant,

Aberdeen, $7 i h M a y, 1861$.

H. AMBROSE SMITH. 